\title{
Política de distribuição de sobras em cooperativas de crédito
}

\author{
Surplus distribution policy in credit union
}

\begin{abstract}
Resumo
As cooperativas de crédito são instituições financeiras que estão cada vez mais presentes no dia a dia das pessoas, devido às taxas atrativas praticadas tanto para o tomador quanto para o poupador de recursos, desempenhando um papel de desenvolvimento social e econômico. São organizações econômicas que não possuem finalidade lucrativa. Desta forma, o benefício ao cooperado é proporcionado principalmente pelas diferenças de taxas e demais serviços oferecidos e o resultado financeiro das cooperativas, denominado sobras, apresenta um papel diferenciado nestas organizações. Visto a pouca participação dos cooperados e possíveis conflitos de interesse entre o cooperado-gestor e demais cooperados, diferentes políticas de distribuição de sobras podem ser tomadas com objetivos específicos. Neste sentido, o presente estudo tem como objetivo avaliar a política de distribuição de sobras nas cooperativas de crédito brasileiras. Foram enviados questionários estruturados para as cooperativas de crédito singulares que haviam e-mails cadastrados no site do Banco Central do Brasil. A amostra final foi de 58 cooperativas com questionários válidos. Os resultados demonstraram que a maioria das cooperativas segue a legislação em relação às reservas indivisíveis e as sobras são majoritariamente destinadas à conta capital. Os achados indicaram que as cooperativas de crédito brasileiras têm priorizado o crescimento do patrimônio líquido. Ressalta, assim, a importância do patrimônio para estas instituições e uma política de retenção das sobras.
\end{abstract}

Palavras-chave: distribuição de sobras, cooperativas de crédito, legislação cooperativista.

\begin{abstract}
Credit unions are financial institutions that are increasingly present in people's daily lives because it has attractive rates for both the borrower and the resource savers. It plays the role of social and economic development. They are economic organizations that do not aim for profit. The benefit to the cooperative is mainly due to differences in rates and other services offered and the financial result of the cooperatives has a different role in these organizations. In view of the low participation of cooperative members and possible conflicts of interest between the cooperative-manager and other cooperative members, different policies for the surplus distribution can be taken with specific objectives. Therefore, we evaluate the policy of distribution of results in Brazilian credit unions. We send structured questionnaires to the singular credit unions that had e-mails registered on the website of the Central Bank of Brazil. The final sample consisted of 58 cooperatives with valid questionnaires. We find that most cooperatives follow the legislation in relation to indivisible reserves and the results are mostly a destination for the capital account. The findings indicate that Brazilian credit unions have prioritized the growth of the equity. It emphasizes, therefore, the importance of the equity for these institutions and policy of retention of results.
\end{abstract}

Keywords: surplus distribution, credit unions, cooperative legislation.

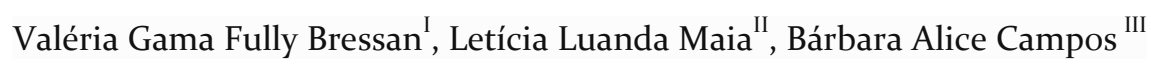

${ }^{\text {I } U n i v e r s i d a d e ~ F e d e r a l ~ d e ~ M i n a s ~ G e r a i s ~(U F M G) . ~ M i n a s ~ G e r a i s, ~ M G, ~ v a l e r i a . f u l l y @ g m a i l . c o m ~}$

${ }^{\text {II }}$ Universidade Federal de Minas Gerais (UFMG). Minas Gerais, MG, leticyaluanda@gmail.com

III Universidade Federal de Minas Gerais (UFMG). Minas Gerais, MG, alice.barbaracs@gmail.com 


\section{Introdução}

As cooperativas são organizações formadas por indivíduos com interesses comuns e que contribuem com bens ou serviços para o exercício de uma atividade econômica (BRASIL, 1971). Segundo dados da Organização das Cooperativas Brasileiras (OCB, 2019), a partir de 2019 as cooperativas são organizadas em sete ramos: produção de bens e serviços, infraestrutura, consumo, transporte, saúde, agropecuário e crédito.

No ramo crédito, tratam-se de instituições financeiras que se assemelham aos bancos quanto ao tipo de operação. Taylor (1971) destaca que assim como nos demais ramos, uma das características das cooperativas de crédito não é o lucro individual, mas sim o alcance dos objetivos econômicos e sociais do grupo. Sendo assim, não possuem finalidade lucrativa, e os benefícios da participação nestas organizações podem ocorrer pela política de preço, prestação de serviços e geração e distribuição de sobras (BARTON et al., 2011).

O foco das cooperativas de crédito não está puramente na obtenção de resultado, mas principalmente no papel social que exercem. Segundo dados do Fundo Garantidor do Cooperativismo de Crédito (FGCOOP, 2017), dos 5570 municípios brasileiros existentes em dezembro de 2017, 551 eram atendidos apenas por cooperativas ou Posto de Atendimento Avançado (PAA), o que correspondem a uma população de 2,92 milhões. Esse dado reforça o papel do cooperativismo de crédito na inclusão financeira e atendendo em locais que seria totalmente desassistido se não fosse o cooperativismo.

As sobras, como o próprio nome sugere, são os recursos não utilizados pela sociedade, os quais devem retornar aos associados, na proporção da utilização de cada um dos serviços da cooperativa (POLONIO, 2001). Para a destinação das sobras devem-se observar as exigências legais de constituição dos fundos obrigatórios indivisíveis: o Fundo de Reserva Legal (mínimo de 10\%) e Fundo de Assistência Técnica, Educacional e Social (FATES) (mínimo de 5\%) (BRASIL, 1971). Barroso (2009) destaca que o restante, após esta destinação obrigatória, pode ser alocado a outros fundos e reservas e rateadas aos cooperados.

De acordo com a Lei Cooperativista no. 5764 de 1971, o retorno das sobras líquidas do exercício ocorre proporcionalmente às operações realizadas pelo associado. Barroso (2009) ressalta que este rateio pode ser em conta capital, ocasionando um aumento do patrimônio líquido, ou em conta corrente do cooperado, o que proporciona sua retirada imediata. A partir deste estudo, Barroso e Bialoskorski Neto (2010) propuseram um modelo de tipificação da distribuição de resultados aos cooperados de cooperativas de crédito com base na alocação em recursos divisíveis ou indivisíveis e em conta capital ou conta corrente. O modelo permite organizar os tipos de classificação e proporciona um melhor entendimento quanto à distribuição de sobras.

Apesar de não ter finalidade lucrativa, é necessário que os empreendimentos cooperativistas apresentem resultado econômico para cumprir sua função social com eficácia (SALES, 2010). A política de distribuição de sobras tem relação direta com o aumento do Patrimônio Líquido (PL). O PL tem um importância ainda maior para as instituições financeiras, visto as exigências de patrimônio de referência.

Advindo de uma necessidade internacional de assegurar as instituições financeiras do risco de crédito, acordos foram realizados nos últimos anos para garantir as exigências de capital impostas para este segmento: acordos de Basileia I, II e III. O Banco Central do Brasil faz parte do Comitê desde 2009 e atualmente a exigência mínima é de $11 \%$ para os bancos e $12 \%$ para cooperativas que possuem filiação a centrais, $14 \%$ para cooperativas centrais e $17 \%$ para singulares independentes (CMN, 2017). Essas exigências podem se relacionar com a forma de distribuição das sobras nas cooperativas de crédito de forma a manter ou atingir o mínimo exigindo.

As formas de distribuições de resultado podem estar associadas às diferentes estratégias de negócios. Seja por uma política de distribuição direta aos cooperados, afetando positivamente a renda dos participantes. Esta política pode estar associada a uma falta de atratividade de investimento nas cooperativas associado ao seu poder decisório não está atrelado ao número de quotas e também a baixa remuneração do capital investido (BESLEY, 1995; HANSMANN, 200o; CHADDAD; COOK, 2004). Ainda como uma forma de manutenção das exigências mínimas de 
capital advinda de uma possível reclassificação das quotas como passivo financeiro, a partir da Interpretação Técnica ICPC 14 (LONDERO; SANTOS, 2019).

Uma terceira alternativa de política de distribuição das sobras estaria associada a constituição de reserva não distribuível como forma de garantir a sustentabilidade da organização. Esta política também se baseia nas características de baixa atratividade de investimento do capital (BESLEY, 1995; HANSMANN, 200o) e pouca clareza dos direitos de propriedade das cooperativas de crédito (TAYLOR, 1971).

As cooperativas são administradas pelos próprios cooperados. Portanto, a figurado do cooperado gestor e do cooperado não gestor. Estes indivíduos podem ter interesses diferentes que refletem na política de distribuição das sobras. Por mais que esta decisão é tomada em assembleia, determinados cooperados podem ter maior poder de influência no grupo, ressaltando o conflito de interesses(HANSMANN, 200o; COSTA, D. R. DE M.; CHADDAD; AZEVEDO, 2012). À luz da Teoria da Agência e governança corporativa, torna-se importante mecanismos para alinhar os interesses e reduzir os conflitos (MUNHOS, 2018). Lima, Araújo e Amaral (2008) apresentam a visão que medidas simples resolveriam o conflito de agência em cooperativas de crédito, como regras bem definidas, regulamentos e supervisão e controles internos eficazes.

Nesta perspectiva, o presente estudo responde a seguinte questão: como as cooperativas de crédito realizam a distribuição de sobras? Utilizou-se da pesquisa qualitativa para avaliar como ocorre a política de distribuição de sobras nas cooperativas de crédito brasileiras. Mais especificamente discute as políticas de distribuição de sobras nas cooperativas de crédito, verifica a estratégia mais utilizada pelas cooperativas brasileiras e compara a prática das cooperativas com o que está previsto na legislação.

Trata-se de uma temática relevante, ainda não discutida no cenário brasileiro. $\mathrm{O}$ trabalho contribui ao apresentar o cenário de distribuição de sobras possibilitando informação útil para os gestores das cooperativas, assim como para os cooperados e potenciais associados. Fornece também resultados relevantes para os sistemas cooperativos, quanto às informações para direcionar ações no que tange a política de distribuição de sobras e levanta o diálogo sobre os aspectos que impactam na política de distribuição de sobras.

As cooperativas foram levantadas via site do Banco Central do Brasil (BCB) e posteriormente foram enviados questionários por e-mail, utilizando-se da amostragem por acessibilidade. Os resultados demonstram que as cooperativas seguem com rigor a legislação e os estatutos que definem um mínimo de sobras indivisíveis. Em relação às sobras divisíveis são, em sua maioria, distribuídas em conta capital, como esperado.

O presente trabalho está estruturado em 5 seções. A seção 2 traz uma revisão de literatura que trata sobre a história do cooperativismo, conflito entre tomadores e poupadores e às formas de distribuição de sobras. A seção 3 apresenta a metodologia da pesquisa e a seção seguinte os resultados após a aplicação do questionário. A última seção apresenta as considerações finais.

\section{O Cooperativismo de Crédito}

Cooperativa de crédito é uma instituição financeira formada pela associação de pessoas para prestar serviços financeiros exclusivamente aos seus associados. Os cooperados são ao mesmo tempo donos e usuários da cooperativa, participando de sua gestão e usufruindo de seus produtos e serviços (BCB, 2017).

Formadas por iniciativa das próprias pessoas que as utilizam, contribuem ao desenvolvimento local sustentável, especialmente nos aspectos de formação de poupança e financiamento de iniciativas empreendedoras, trazendo benefícios à comunidade em termos de geração de empregos e distribuição de renda (FAIRBAIRN et al., 1997; SOARES; MELO SOBRINHO, 2008).

Segundo a Lei das Cooperativas (5764/1971), são consideradas cooperativas: (i) singulares, as constituídas pelo número mínimo de vinte pessoas físicas, sendo excepcionalmente permitida a admissão de pessoas jurídicas que tenham por objeto atividades econômicas iguais ou correlatas às das pessoas físicas ou, ainda, atividades sem fins lucrativos; (ii) cooperativas centrais ou federações 
de cooperativas, as constituídas de, no mínimo, três singulares, podendo, excepcionalmente, admitir associados individuais; e (iii) confederações de cooperativas, as constituídas de, pelo menos, três federações de cooperativas ou cooperativas centrais, da mesma ou de diferentes modalidades (BRASIL, 1971).

No fim de 2017, o Brasil contava com quatro confederações (Sicredi, Sicoob, Unicred e Cresol), 35 centrais, 967 cooperativas singulares e dois bancos cooperativos em atividade (Bansicredi e Bancoob). Das cooperativas singulares, $724(74,87)$ estão filiadas a um dos 4 sistemas cooperativos existentes e as demais $223(25,13 \%)$ são consideradas cooperativas solteiras ou independentes por não estarem vinculadas a algum sistema de abrangência nacional (BCB, 2017).

Os dois principais Sistemas do Cooperativismo de Crédito Brasileiro são Sicredi e Sicoob. O sistema Sicredi teve sua origem no Rio Grande do Sul e espalhou-se pelo oeste brasileiro, avançando pelos estados do Paraná, Mato Grosso Sul e Mato Grosso. Encontra-se presente em 10 estados brasileiros, mas é o Rio Grande do Sul que apresenta em torno de $55 \%$ dos volumes administrados pelo sistema. Quanto ao Sicoob, este atua em praticamente todo o território nacional com grande ênfase em São Paulo e Minas Gerais que juntos representam 63\% do total do sistema (PORTAL DO COOPERATIVISMO FINANCEIRO, 2017).

A filiação em um sistema cooperativista proporciona suporte para as cooperativas singulares. As centrais exercem um papel de assistência, organização e orientação das atividades (BRASIL, 1971). O suporte oferecido por elas é tão significativo que, inclusive, a participação em uma central reduz exigências de limites mínimos de capital integralizado e Patrimônio Líquido (PL) e limites de exposição por cliente, estabelecidos pela resolução do Conselho Monetário Nacional (CMN) no 4434/2015 (CMN, 2015).

O cooperativismo no Brasil destaca-se na 16º posição no ranking de países do mundo com expressão no cooperativismo de crédito e representa $18 \%$ das agências bancárias do país (PORTAL DO COOPERATIVISMO FINANCEIRO, 2017). O crescimento das cooperativas de crédito no Brasil nos últimos 10 anos é acompanhado do crescimento da quantidade de empréstimos realizados por elas. Apesar de uma brusca diminuição quando comparado com 2015, a quantidade de contratos de crédito realizados pelas cooperativas aos seus associados aumenta a taxas positivas, ao contrário dos bancos comerciais que mantiveram a tendência de crescimento a taxas decrescentes, que exigem mais garantias para a tomada de empréstimos (OBSERVATÓRIO DE COOPERATIVAS, 2017). O gráfico a seguir ilustra essa diferença em relação à quantidade de operações de crédito nos últimos anos para as cooperativas e para os bancos Itaú, Bradesco e Santander.

Figura 1 - Diferença em relação à quantidade de operações de crédito nos últimos anos para as cooperativas e para os bancos Itaú, Bradesco e Santander.

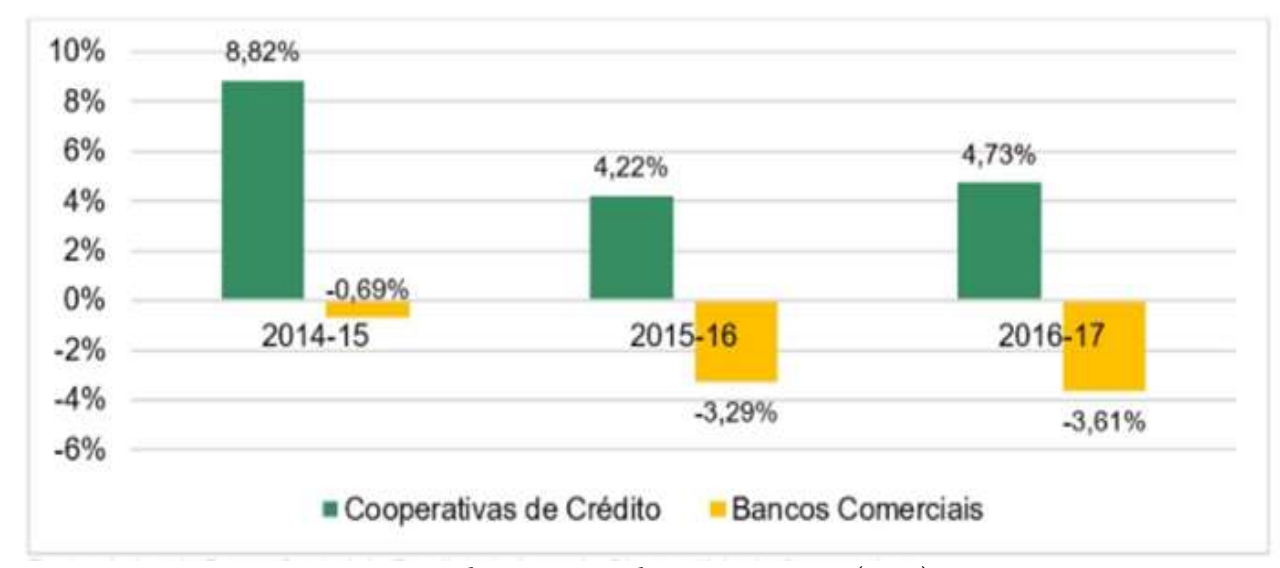

Fonte: Observatório de Cooperativas (2017).

Os dados reforçam a importância do cooperativismo de crédito, seu fortalecimento e crescimento das operações e participação no Sistema Financeiro Nacional, principalmente atuando como ferramenta de inclusão financeira. 
As cooperativas apresentam uma série de atributos diferenciais em comparação a instituições financeiras não cooperativas, em termos de propriedade e governança. Primeiro, não há um grupo de proprietários separado de outros stakeholders, sendo na verdade de propriedade de seus membrosusuários. Segundo, os títulos de propriedade não são transferíveis, nem estão associados à riqueza comum acumulada na organização. Terceiro, essa riqueza comum acumulada, não retirável pelos membros, é gerada unicamente pela retenção de superávits obtidos a partir de transações com os próprios membros. E quarto, a decisão é estabelecida à base de um homem igual a um voto (DAVIS, 2001).

Cooperativas de crédito realizam a mesma atividade de intermediação financeira que as instituições financeiras não cooperadas, com o diferencial de não visarem à maximização do lucro. Isso porque, as operações de captação e de aplicação de recursos são realizadas com os próprios sócios (PHILLIPS, 1953; PINHO, 1977).

Considerando que as cooperativas existem para prestar serviços aos sócios, elas devem ter condições de oferecer-lhes tais serviços de forma vantajosa. Sendo assim, os cooperados sócios dessas organizações deveriam observar vantagens na transação financeira com elas em comparação a alternativas disponíveis no mercado, seja por custos menores para empréstimos, retornos maiores para depósitos, tarifas menores para serviços, ou ainda devolução de eventuais resíduos operacionais (sobras), entre possivelmente outros benefícios diferenciais possíveis (KALUF, 2005).

Barton et al. (2011) destacam que os benefícios aos cooperados podem ocorrer de três formas: através da distribuição de sobras, prestação de serviços e preços diferenciados. Um conjunto de decisões gerenciais com impacto tanto sobre os benefícios diferenciais oferecidos por cooperativas de crédito, quando sobre seus fundamentos de continuidade diz respeito à geração e à distribuição dos resultados líquidos operacionais - sobras em se tratando de cooperativas. Por meio delas, tem-se à disposição recursos passíveis de serem capitalizados no patrimônio líquido da cooperativa disponíveis para aumento de capital de giro ou para aumento de ativos permanentes - ou ainda passíveis de serem devolvidos aos cooperados. Com as sobras ao final de cada exercício, têm-se recursos para fortalecimento da organização cooperativa e para distribuição aos sócios cooperados (BARROSO, 2009).

\section{Formação e Distribuição das Sobras}

Como as cooperativas de crédito não possuem o objetivo de lucrar, e sim propiciar aos cooperados melhores condições para suas atividades particulares, tudo aquilo que é visto como lucro é chamado de sobras. Para Franke (1973), as diferenças positivas entre as receitas e as despesas apuradas nos balanços anuais podem ter uma aparência de lucro. Na realidade, porém, trata-se de sobras resultantes de haver o quadro associativo pago a mais pelos serviços que a cooperativa lhe prestou, ou, inversamente, de ter ela retido um valor excessivo como contraprestação do serviço fornecido.

As sobras, tecnicamente, não são lucros, mas saldos de valores obtidos dos associados para cobertura de despesas, e que, pela racionalização com que a cooperativa trabalhou, não foram gastos. Ainda tendo como base a legislação cooperativista vigente (Lei 5.764/71), em seu artigo 21, inciso IV, determina que as sociedades cooperativas devem estabelecer a forma de devolução das sobras registradas aos associados ou o rateio das perdas apuradas por insuficiência de contribuição para cobertura das despesas da sociedade. Essa distribuição se dá através de três critérios: (1) destinação das sobras para reservas e fundos indivisíveis; (2) rateio das sobras a serem devolvidas aos cooperados, (integralizado no capital do cooperado); e (3) forma efetiva de devolução delas em forma de rateio (crédito em conta corrente do cooperado).

Primeiramente decide-se quanto das sobras irão paras as reservas individuais, de propriedade da sociedade cooperativa, e quanto se devolve aos cooperados, respeitando-se as destinações mínimas obrigatórias definidas na legislação cooperativista brasileira e as definidas nos estatutos das cooperativas. Depois, define-se uma regra para divisão do spread da intermediação financeira entre os cooperados poupadores e tomadores. Rateadas as sobras divisíveis aos cooperados de cooperativas de crédito, define-se a forma de restituição, que pode ser por depósito em conta corrente, de 
disponibilização imediata, ou por integração de capital. Neste último caso, torna indisponível imediatamente aos sócios, embora seja reconhecido como investimento pessoal (BARROSO, 2009).

Para desenvolver o estudo das formas de distribuição de sobras em cooperativas de crédito, Barroso (2009) propôs um modelo de tipificação dessas organizações que será adotado na presente pesquisa. Na figura 2 estão ilustradas as possíveis destinações das sobras totais geradas nas cooperativas de crédito.

Figura 2 - Distribuição das sobras, especificamente para cooperativas de crédito.

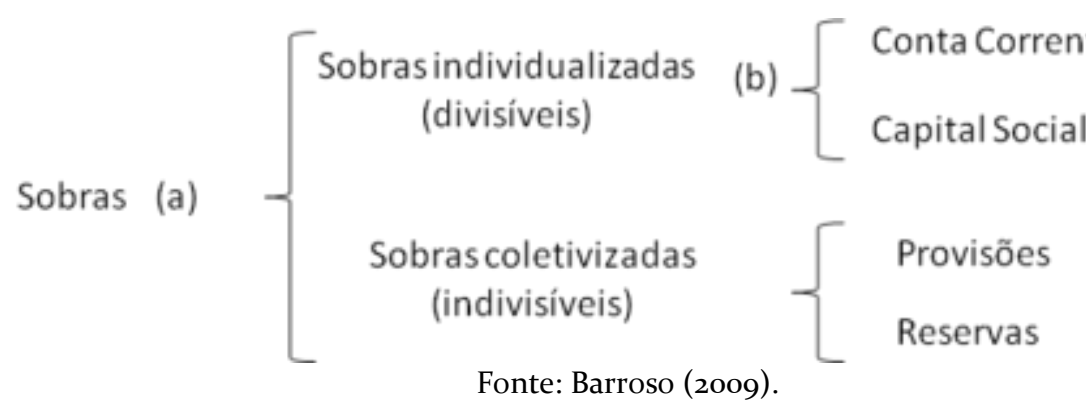

A tipificação da distribuição de sobras proposta é elaborada analisando-se os resultados de duas decisões: (a) a divisão das sobras a destinos divisíveis ou indivisíveis aos cooperados e (b) a definição quanto à devolução das sobras divisíveis em conta corrente ou em conta de capital social. No âmbito dessas definições, ocorre todo o possível conjunto limitado de estratégias de distribuição de resultados aos cooperados (BARROSO, 2009):

(1) Destinação das sobras a reservas e provisões indivisíveis, em limites superiores aos exigidos pela legislação, não ocorrendo, portanto, distribuição delas de forma individualizada aos cooperados;

(2) Destinação de parte das sobras a reservas e provisões divisíveis e da parte restante ao capital social individual dos cooperados, no patrimônio líquido da cooperativa e, portanto, indisponível imediatamente a eles; e

(3) Destinação de parte das sobras a reservas e provisões divisíveis e da parte restante diretamente aos cooperados nas respectivas contas correntes, passível de utilização imediata.

$\mathrm{Na}$ tabela 1 estão indicados os cálculos das sobras totais geradas aos cooperados e as respectivas contabilizações que geram os valores a serem considerados neste cálculo.

Tabela 1 - Cálculo das sobras totais geradas aos cooperados.

\begin{tabular}{|c|c|}
\hline ITEM DE CÁLCULO & CONTABILIZAÇÃO DE ORIGEM \\
\hline $\begin{array}{l}\text { Total de Ingressos } \\
\text { (-) Total de Dispêndios } \\
\text { (=) Sobras Líquidas do exercício } \\
\text { (+) Baixa de Reserva de reavaliação } \\
\text { (+) Resultado do exercício anterior } \\
\text { (+) Capitalização de reservas de lucros } \\
\text { (+) Juros sobre capital próprio (líquido) }\end{array}$ & $\begin{array}{l}\text { Contas de resultado credoras a Sobras e perdas acumuladas } \\
\text { Sobras e perdas acumuladas a Contas de resultado devedoras } \\
\text { Reserva de reavaliação a Sobras e perdas acumuladas } \\
\text { Diversos (ajuste do exercício anterior) a Sobras e perdas acumuladas } \\
\text { Reservas de lucros a Capital Social } \\
\text { Despesas de juros ao capital } \\
\text { a Reservas especiais de lucros } \\
\text { a Dividendos e bonificações a pagar }\end{array}$ \\
\hline
\end{tabular}

Depois de calculado o total de sobras geradas aos cooperados, separa-se o quanto é destinado de forma individual aos cooperados e quanto é tornado indivisível. A parte individualizada é composta pelo montante do resultado devolvido aos cooperados em conta corrente, mais o montante capitalizado individualmente. Este, por sua vez, é resultado da devolução do resultado em 
conta de capital social, mais a transferência ao capital a partir de reservas de lucros e mais os juros sobre capital próprio pagos no exercício, conforme demonstrado na tabela 2

Tabela 2 - Cálculo da parcela das sobras individualizada aos cooperados.

\begin{tabular}{ll}
\hline ÍTEM DE CÁLCULO & CONTABILIZAÇÃO DE ORIGEM \\
\hline Devolução de sobras aos cooperados em conta corrente & Sobras ou Perdas Acumuladas a Depósitos à Vista \\
(+) Devolução de sobras aos cooperados em conta capital & Sobras ou Perdas Acumuladas a Capital Social \\
(+) Capitalização de reservas de lucro & Reservas de lucros a Capital Social \\
(+) Juros sobre capital próprio (líquido) & Despesas de juros ao capital \\
& a Reservas especiais de lucros \\
\hline (=) Sobras individualizadas (divisíveis) & a Dividendos e bonificações a pagar \\
\hline
\end{tabular}

Fonte: adaptado de Barroso e Bialoskorski Neto (2010).

A parte coletivizada das sobras totais geradas aos cooperados é composta pela somatória dos montantes destinados à Reserva Legal, à composição de outras Reservas de Lucros, à composição do Fundo de Assistência Técnica, Educacional e Social (FATES) e à composição de outros fundos que tenham sido criados na cooperativa com essa característica de indivisibilidade (BARROSO, 2009). O cálculo está indicado na tabela 3.

Tabela 3 - Cálculo da parcela das sobras coletivizada ao quadro social da cooperativa.

\begin{tabular}{ll}
\hline ITEM DE CÁLCULO & CONTABILIZAÇÃO DE ORIGEM \\
\hline Composição de reserva legal & Sobras ou Perdas Acumuladas a Reserva Legal \\
(+) Composição de outras reservas de lucros & Sobras ou Perdas Acumuladas \\
& A Reservas estatuárias \\
& A Reservas para contingências \\
& A Reservas para expansão \\
& A Reservas de lucros a realizar \\
(+) Composição do FATES & A Reservas especiais de lucros \\
& Sobras ou Perdas Acumuladas \\
(+) Composição de outros fundos indivisíveis que & A Fundo de Assistência Técnica, Educacional e Social \\
tenham sido criados na cooperativa & Cobras ou Perdas Acumuladas a Diversos (específico em cada \\
\hline (=) Sobras coletivizadas (indivisíveis) &
\end{tabular}

Fonte: adaptado de Barroso e Bialoskorski Neto (2010).

Destaca-se que a Lei 5.764/71 determina a criação obrigatória de dois fundos indivisíveis: Fundo de Reserva Legal (FRL) e FATES. O primeiro é constituído pelo mínimo de $10 \%$ das sobras e tem por finalidade reparar perdas e atender ao desenvolvimento das atividades da cooperativa. O segundo, FATES, constituído pelo mínimo de $5 \%$ das sobras e $100 \%$ do resultado de atos não cooperativos (operações realizadas com não cooperados). O FATES é destinado à prestação de assistência aos associados, seus familiares e empregados da cooperativa. Destaca-se que para as cooperativas de crédito, o FATES é classificado como passivo (BCB, 2006).

Após a constituição dos dois fundos obrigatórios, têm-se o que é denominado de Sobras à Disposição da Assembleia Geral, que decidirá pela destinação final do recurso. Vale destacar o uso dos termos fundo e reserva como sinônimos em vários documentos normativos. A própria Norma Brasileira de Contabilidade, Interpretação Técnica Geral (ITG) no 2004 de 2017, aplicável às cooperativas ressalta: "fundos constituídos de sobras líquidas, previstos na legislação ou no estatuto social, nesta interpretação, são denominados Reservas" (ITG 2004, 2017).

Uma vez verificada as divisões das sobras totais nos montantes divisíveis e indivisíveis, foi proposto por Barroso (2009)o seguinte modelo de tipificação da distribuição de sobras em cooperativas de crédito, conforme tabela 4. 
Tabela 4 - Descrição do modelo para tipificação da distribuição de resultados aos cooperados de cooperativas de crédito.

\begin{tabular}{cll}
\hline $\begin{array}{c}\text { TIPO DE } \\
\text { COOPERATIVA }\end{array}$ & $\begin{array}{l}\text { ESPECIFICAÇÃO } \\
\text { (quanto à distribuição das sobras } \\
\text { totais geradas aos cooperados) }\end{array}$ & DESCRIÇÃO \\
\hline I & $\begin{array}{l}\text { Alguma parte das sobras devolvida } \\
\text { em dinheiro na Conta Corrente dos } \\
\text { cooperados }\end{array}$ & $\begin{array}{l}\text { Cooperativas que devolvem alguma parte do resultado em } \\
\text { dinheiro nas contas correntes dos cooperados. }\end{array}$ \\
II & $\begin{array}{l}\text { Maior parte das sobras devolvida no } \\
\text { Capital Social dos cooperados }\end{array}$ & $\begin{array}{l}\text { Cooperativas que devolvem maior parte dos resultados nas } \\
\text { contas capital social dos cooperados do que em reservas } \\
\text { indivisíveis: não há devolução em conta corrente. } \\
\text { Cooperativas que devolvem maior parte dos resultados às } \\
\text { reservas e provisões indivisíveis do que nas contas capital } \\
\text { social dos cooperados; também não há devolução em conta } \\
\text { corrente. }\end{array}$ \\
\hline III & $\begin{array}{l}\text { Maior parte das sobras destinadas a } \\
\text { reserva/provisões Indivisíveis }\end{array}$ & Fonte: adaptado de Barroso e Bialoskorski Neto (2010).
\end{tabular}

A forma de destinação das sobras, seja alocando no Patrimônio Líquido ou devolvendo ao proprietário, impacta no saldo do PL das cooperativas de crédito. As instituições financeiras, incluindo cooperativas deste segmento, demanda atender exigências mínimas de capital para realização das atividades financeiras.

\section{Teoria da Agência e Políticas de Distribuição de Sobras}

A Teoria da agencia tem seu início com o trabalho de pesquisadores norte-americanos Berle e Means em 1932, que identificaram o conflito de agência. Em 1976, Jensen e Meckling publicam estudos mencionando o que convencionaram chamar de problema de agente-principal (que deu origem à Teoria da Firma ou Teoria do Agente-Principal). Nesta teoria, as empresas são consideradas um nexo de contratos imperfeitos. A imperfeição ocorre porque o contrato não consegue prever em cláusulas todos os possíveis cenários (BERLE; MEANS, 1932; JENSEN; MECKLING, 1976; LIMA; ARAÚJO; AMARAL, 2008).

Visto que os contratos são imperfeitos, a relação entre agente (o que executa, na figura do gestor) e principal (proprietário) gera um cenário de conflitos de interesses. Parte do direito de controle do proprietário é transferido ao agente, ao delegar a autoridade de agir no nome do principal. Esta situação é denominada relação de agência. Entretanto, cada indivíduo buscará maximizar sua utilidade, o que leva a decisões conflituosas (conflito de agência) (HANSMANN, 2000).

Aquele que está no controle pode usufruir de benefícios privados. Surgem, então, custos que busquem reduzir o conflito (os custos de agências), como monitoramento e Bonding Cost (Concessão de garantias) (HANSMANN, 200o). Nos casos que os gestores também são proprietários, há o incentivo do oportunismo gerencial. O gestor-proprietário receberá todo o benefício do gerenciamento, porém compartilhando o custo de propriedade com todos os proprietários. Este cenário ocorre nas cooperativas. (COOK, 1995) destaca que cooperativas apresentam direitos de propriedade vagamente definidos. Sendo assim, deveriam promover a separação entre proprietários e gestores, pois essa desvinculação gera benefícios para a empresa.

Como nestas organizações os cooperados (proprietários) também são clientes que podem ter dois perfis bens distintos, poupadores ou tomadores, o conflito pode ocorrer entre esses perfis. Assim, duas formas de conflito de agência podem ocorrer em cooperativas de crédito: entre proprietários $\mathrm{x}$ gestores ou tomadores $\mathrm{x}$ poupadores. No primeiro caso é devido à falta de separação entre propriedade e gestão (CUEVAS; FISCHER, 2006).

Costa e Melo (2017) avaliaram o conflito de agência em duas cooperativas de crédito mineiras. Identificaram assimetria informacional e problemas de monitoração devida as dificuldades de participação direta via delegados eleitos democraticamente. Também observaram um domínio da organização por membros do corpo diretivo e baixa rotatividade nos órgãos de gestão. Desta forma, 
com a permanência na gestão e maior poder de influência, estes indivíduos podem direcionar as políticas das cooperativas, inclusive no que tange a distribuição de resultado.

Fontes Filho, Marucci e Oliveira (2008) também apontam o problema de informação principalmente por conta da baixa participação nas assembleias e nos processos eleitorais, seja por confiança ou não compreensão da importância. A baixa participação, visto que as distribuições de resultado são definidas em assembleias, deixa mais flexível esta decisão às custas dos gestores.

Visto essa flexibilizada de gestão, os gestores podem adotar diferentes políticas de distribuição de resultados para alcançar objetivos específicos. Uma distribuição direta aos cooperados, em conta capital, tem um impacto positivo na renda dos cooperados. Tal estratégia pode ser utilizada como um marketing pela cooperativa, e até como forma de atrair mais capitalização pela integralização de novos cooperados. A literatura aponta que as quotas possuem baixa atratividade de investimento por não apresentar poder decisório atrelado ao número de quotas (um homem, um voto) e pela baixa remuneração do capital investido (BESLEY, 1995; HANSMANN, 200o; CHADDAD; COOK, 2004).

Outra estratégia associada a politica de distribuição de sobras o uso para aumento do capital social, visando a manutenção das exigências mínimas de capital advinda dos Acordos de Basiléia. Estes acordos criaram exigências mínimas de capital próprio principalmente para assegurar os riscos de crédito (JUCÁ, 2011). O Banco Central do Brasil faz parte do Comitê de Basileia desde 2009. Conforme dados do Banco Central do Brasil, três principais acordos foram estabelecidos pelo Comitê de Basileia: Basileia I, II e III. Basileia I ocorreu em 1988 com a introdução de capital mínimo e criando o Índice de Basileia (Î́ndice Mínimo de Capital para Cobertura do Risco de Crédito). O segundo Acordo (Basileia II), aconteceu em 2004 e apresentou como pontos principais a introdução de 3 (três) pilares: (1) requerimentos de capital para cobertura de riscos de crédito, mercado e operacional; (2) processo de avaliação; e (3) disciplina do mercado pela exigência de divulgação de informação (BCB, 2019b).

Em 2010 ocorreu o Acordo de Basileia III com o aprimoramento dos acordos anteriores. As principais inovações trazidas por este acordo foram: elevação da qualidade e quantidade do capital regulatório; aperfeiçoamento dos fatores para a ponderação de ativos pelo risco; introdução dos buffers (colchões) de capital para conservação e contracíclico; novos requerimentos de liquidez e alavancagem e requisitos prudenciais para as instituições sistêmicas (BCB, 2019b). No Brasil, Basileia III vem sendo implantado desde 2013 e o Regime Prudencial Simplificado (RPS) foi definido pela Resolução CMN no 4.194/2013 (CMN, 2013), posteriormente modificada pela Resolução CMN no 4.606/2017 (CMN, 2017). Atualmente a exigência mínima do Índice de Basileia é de $11 \%$ e para as cooperativas quem adota o RPS as taxas $12 \%$ para cooperativas filiadas, $14 \%$ para cooperativas centrais e $17 \%$ para singulares independentes.

Uma terceira política atrelada a constituição de reserva não distribuível estaria associada a uma forma de garantir a sustentabilidade das cooperativas. Esta política também se baseia nas características de baixa atratividade de investimento do capital (BESLEY, 1995; HANSMANN, 200o) e pouca clareza dos direitos de propriedade das cooperativas de crédito (TAYLOR, 1971).

\section{Metodologia}

O presente estudo trata-se de uma pesquisa descritiva e qualitativa. As pesquisas descritivas têm como objetivo descrever as características de determinadas populações ou fenômenos ou o estabelecimento de relações entre variáveis e uma de suas características mais relevante na utilização de técnicas padronizadas de coleta de dados, tais como questionário e a observação sistêmica (GIL, 2008). Esse tipo de pesquisa busca descrever um fenômeno ou situação em detalhe, especialmente o que está ocorrendo, permitindo abranger, com exatidão, as características de um indivíduo, uma situação, ou um grupo, bem como desvendar a relação entre os eventos (SELLTIZ; WRIGHTSMAN; COOK, 1965). Não há interferência do pesquisador, sendo ele apenas um mero descritor da situação. Desta forma, a presente pesquisa pode ser considerada como descritiva, porque apresenta características econômico-financeiras das cooperativas singulares de crédito obtidas a partir de um questionário aplicado nas instituições. 
O estudo realizado pode ser considerado ex post facto, uma vez que foram avaliadas as demonstrações financeiras das cooperativas singulares entre 2014 e 2016 . A investigação ex post facto se refere a um fato que já aconteceu, sendo que este tipo de pesquisa é utilizado quando o pesquisador não pode controlar ou manipular as variáveis, seja porque suas manifestações já ocorreram, seja porque as variáveis não são controláveis (VERGARA, 200o).

Inicialmente, foi elaborado um questionário com questões relativas à caracterização da cooperativa, às sobras acumuladas no período e suas destinações. Esse questionário foi submetido a um pré-teste junto à diretora executiva de uma Cooperativa de Crédito filiada ao Sicoob e foi ajustado após as considerações desta diretora.

O questionário estruturado foi enviado às cooperativas singulares cadastradas no site do $\mathrm{BCB}$, por e-mail, com a utilização da ferramenta Google Docs. A coleta aconteceu dentre do período de 20/07/2017 a 31/08/2017. O questionário foi enviado a 1.030 cooperativas de crédito, que possuíam o e-mail disponibilizado no cadastro no site do BCB em dezembro de 2016. Desse conjunto, apenas 58 cooperativas responderam ao questionário, refletindo uma taxa de 5,63\% de resposta. Após a coleta de dados via questionário, foram analisadas as respostas e feita a relação quanto a tipificação da distribuição de resultados aos cooperados de cooperativas de crédito propostos por Barroso e Bialoskorski Neto (2010).

\section{Análise e Discussão dos Resultados}

Dentre os 58 questionários respondidos, a maioria foi preenchida por gerentes e diretores das cooperativas de crédito de todo o território brasileiro. A tabela 5 apresenta a quantidade de cooperativas de crédito por estado, participantes da pesquisa.

Tabela 5 - Estados das Cooperativas de Crédito singulares participantes da pesquisa

\begin{tabular}{cccc}
\hline UF & Frequência & Porcentagem & Acumulado \\
\hline CE & 1 & 1,72 & 1,72 \\
PA & 1 & 1,72 & 3,44 \\
SE & 1 & 1,72 & 5,16 \\
ES & 3 & 5,17 & 10,33 \\
MT & 3 & 5,17 & 15,50 \\
PE & 3 & 5,17 & 20,67 \\
SC & 3 & 5,17 & 25,84 \\
GO & 4 & 6,90 & 32,74 \\
PR & 4 & 6,90 & 39,64 \\
BA & 5 & 8,62 & 48,26 \\
RS & 7 & 12,07 & 60,33 \\
MG & 11 & 18,97 & 79,30 \\
SP & 12 & 20,69 & 100,00 \\
\hline Total & 58 & 100, oo \\
\hline \multicolumn{5}{c}{}
\end{tabular}

Observa-se uma maior concentração de Cooperativas dos estados da região sudeste: São Paulo (12) e Minas Gerais (11). Esta região é a que apresenta a maior quantidade de cooperativas de crédito singulares. Segundo dados do (BCB, 2019a), em dezembro de 2016, 21,88\% das cooperativas de crédito singulares são de São Paulo e $18,45 \%$ de Minas gerais, correspondendo aos estados com maior número de cooperativas de crédito. A região sudeste compreende 48,o9\% das cooperativas de crédito, seguida da região sul com 30,91\%. Apesar da baixa taxa de resposta dos questionários, consegue-se abranger estados diferentes e com uma predominância das regiões com maior número de cooperativas, mostrando uma representatividade qualitativa da amostra.

Conforme apresentado pela lei das cooperativas, as singulares podem se filiar a sistemas que garantem certo apoio às suas atividades. A tabela a seguir apresenta a distribuição das cooperativas da amostra, por central. 
Tabela 6 - Sistemas das Cooperativas de Crédito Singulares

\begin{tabular}{cccc}
\hline Sistema & Frequência & Porcentagem & Acumulado \\
\hline CECRERS & $\mathbf{1}$ & $\mathbf{1 , 7 2}$ & $\mathbf{1 , 7 2}$ \\
CRESOL & $\mathbf{2}$ & 3,45 & 5,17 \\
SICOOB & $\mathbf{2 8}$ & $48, \mathbf{2 8}$ & 53,45 \\
SICREDI & $\mathbf{1 4}$ & $\mathbf{2 4 , 1 4}$ & $\mathbf{7 7 , 5 9}$ \\
SOLTEIRA/INDEPENDENTE & $\mathbf{1 2}$ & $\mathbf{2 0 , 6 9}$ & $98, \mathbf{2 8}$ \\
UNICRED & $\mathbf{1}$ & $\mathbf{1 , 7 2}$ & $\mathbf{1 0 0 , 0 0}$ \\
\hline Total & $\mathbf{5 8}$ & $\mathbf{1 0 0 , 0 0}$ \\
\hline \multicolumn{5}{c}{ Fonte: Dados da pesquisa. }
\end{tabular}

Destaca-se que os respondentes estão associados majoritariamente aos sistemas Sicoob (28) e Sicredi (14). Conforme os dados apresentados do BCB (2017), estes sistemas são os que mais apresentam cooperativas filiadas, $46,52 \%$ e $11,58 \%$, respectivamente. Ademais, o Portal do Cooperativismo Financeiro (2017) destaca que tratam de sistemas bem consolidados e representativos para o segmento.

É notório destacar também a presença de cooperativas independentes dentro da amostra (14 cooperativas). No período de análise (2014 a 2016), as cooperativas solteiras eram 195, o que representa $19,14 \%$. Vale destacar, conforme apresentado no referencial teórico, a não filiação a uma central leva a maiores exigências a estas cooperativas estabelecidas na resolução CMN no 4434/2015, inclusive no que tange ao capital mínimo.

Também se analisou a idade das cooperativas, para se ter uma visualização do tempo de experiência e possível maturidade das organizações. A tabela 7 apresenta a frequência da idade.

Tabela 7 - Idade das cooperativas de Crédito Singulares

\begin{tabular}{|c|c|c|c|}
\hline Idade & Frequência & Porcentagem & Acumulado \\
\hline Abaixo de 10 anos & 3 & 5,17 & 5,17 \\
\hline De 11 a 20 anos & 14 & 24,14 & 29,31 \\
\hline De 21 a 30 anos & 24 & 41,38 & 70,69 \\
\hline De 31 a 40 anos & 9 & 15,52 & 86,21 \\
\hline De 41 a 50 anos & 4 & 6,90 & 93,10 \\
\hline De 51 a 60 anos & 2 & 3,45 & 96,55 \\
\hline De 91 a 100 anos & 1 & 1,72 & 98,28 \\
\hline Acima de 100 anos & 1 & 1,72 & 100,00 \\
\hline Total & 58 & 100 & \\
\hline
\end{tabular}

Destaca-se que as cooperativas já estão no mercado em grande parte há mais de 10 anos. Apenas 5,17\% possui idade menor. Em estudo realizado pelo Sebrae (2014) encontrou que 24,4\% das empresas brasileiras fecham nos primeiros dois anos. Isso reforça a dificuldade das organizações em seus primeiros anos, sendo as entidades mais antigas possivelmente mais maduras e estabilizadas.

Adentra-se agora, na análise quanto à ocorrência e forma de distribuição das sobras no período de 2014 a 2016. A tabela 8 apresenta os resultados sobre a ocorrência de sobras no período analisado.

Tabela 8 - Ocorrência de Sobras no Período Analisado

\begin{tabular}{cccc}
\hline Ano & Resultado Positivo & Resultado Negativo & TOTAL \\
\hline 2016 & $53(91 \%)$ & $5(9 \%)$ & $58(100 \%)$ \\
2015 & $55(95 \%)$ & $3(5 \%)$ & $58(100 \%)$ \\
2014 & $54(93 \%)$ & $4(7 \%)$ & $58(100 \%)$ \\
\hline
\end{tabular}

Fonte: Dados da pesquisa.

Observa-se que o número de cooperativas que apresentaram resultado positivo (sobras) é significativamente maior do que aquelas que não apresentaram resultado positivo. Apenas uma 
cooperativa não apresentou sobras em nenhum período. Em contrapartida, 49 (84,48\%) das cooperativas apresentaram resultado positivo nos todos os três anos analisados.

As sobras correspondem às diferenças entre as receitas e as despesas apuradas no exercício (FRANKE, 1973). As cooperativas, como organizações que tem um papel social muito importante não tem um enfoque em auferir grandes resultados. A própria legislação competente ressalta não haverem finalidades lucrativas. Porém, o resultado positivo é importante para os diversificados investimentos nas organizações, o que pode pautar a presença significativa de sobras nas cooperativas de crédito analisadas (SALES, 2010).

Em relação ao montante das sobras e os valores destinados ao FATES e RFL, as estatísticas descritivas são apresentadas na tabela 9 .

Tabela 9 - Sobras Antes das Destinações e destinações às reservas obrigatórias

\begin{tabular}{cccccc}
\hline Variável & Obs. & Média & DP & Mínimo & Máximo \\
\hline sobras2016 & 51 & $6.797 .113,00$ & $14.900 .000,00$ & $-9.435,35$ & $89.000 .000,00$ \\
sobras2015 & 53 & $5.561 .438,00$ & $11.400 .000,00$ & $3.296,57$ & $61.000 .000,00$ \\
sobras2014 & 52 & $5.069 .439,00$ & $10.400 .000,00$ & $17.284,28$ & $64.000 .000,00$ \\
FATES2016 & 52 & $6,56 \%$ & $2,52 \%$ & $5,00 \%$ & $15,00 \%$ \\
FATES2015 & 56 & $6,43 \%$ & $2,47 \%$ & $5,00 \%$ & $15,00 \%$ \\
FATES2014 & 55 & $6,51 \%$ & $2,49 \%$ & $5,00 \%$ & $15,00 \%$ \\
FRL2016 & 50 & $26,44 \%$ & $20,50 \%$ & $10,00 \%$ & $77,00 \%$ \\
FRL2015 & 55 & $26,91 \%$ & $22,12 \%$ & $10,00 \%$ & $100,00 \%$ \\
FRL2014 & 54 & $25,74 \%$ & $20,64 \%$ & $10,00 \%$ & $75,00 \%$ \\
FundosT2016 & 50 & $33,33 \%$ & $20,24 \%$ & $15,00 \%$ & $82,00 \%$ \\
FundosT2015 & 55 & $33,27 \%$ & $21,71 \%$ & $15,00 \%$ & $100,00 \%$ \\
FundosT2014 & 54 & $32,28 \%$ & $20,82 \%$ & $15,00 \%$ & $83,00 \%$ \\
\hline
\end{tabular}

Observações: DP: Desvio Padrão. FATES: Fundo de Assistência Técnica Educacional e Social. FRL: Fundo de Reserva Legal. FundosT corresponde a soma de FATES e FRL. FATES possui taxa mínima de $5 \%$, conforme Lei $n^{\circ} 5 \cdot 764 / 71$. FRL possui taxa mínima de $10 \%$, conforme Lei $\mathrm{n}^{\circ} 5 \cdot 764 / 71$. O valor abaixo de 58 de obs. (observações) se deu por não ter sido informado ou pelo resultado negativo, no caso da destinação aos fundos.

Fonte: Dados da pesquisa.

Os valores médios das sobras para os anos 2014, 2015 e 2016 são mais de 5 milhões, 5,5 milhões e 6,7 milhões, respectivamente. Do total de sobras entre 2014 e 2016 antes das destinações, é notório o crescente aumento de capital, salvo algumas exceções que reduziram o volume e até mesmo ficaram com saldo negativo, em 2016.

Destaca-se que algumas cooperativas apresentam montantes menores de sobras, na ordem dos milhares, mas é expressivo a quantidade de cooperativas com resultado acima de 1 milhão (31, 31 e 39 das 58 da amostra, para os anos de 2016, 2015 e 2014, respectivamente). Este valor alto de sobras seguem a tendência de crescimento das sobras já apresentado por Barroso e Bialoskorski Neto (2010) para as cooperativas de crédito singulares brasileiras no período de 2001 a 2007. Lauschner (1984) destaca o potencial uso das sobras para captação de recursos próprios pelas cooperativas, o que pode justificar a geração de sobras. Ademais, conforme apresentado por Barton et al. (2011), a distribuição de resultado também é um benefício das cooperativas ao cooperado, apesar de não ser o principal.

Quanto à destinação das reservas obrigatórias FATES (Fundo de Assistência Técnica, Educacional e Social) e FRL (Fundo de Reserva Legal), é notório que todas as cooperativas analisadas seguem a legislação no que tange à destinação mínima de 5\% para o FATES e 10\% para o FRL. A tabela a seguir apresenta a quantidade de cooperativas que destinaram o mínimo exigido por lei para cada um dos fundos. 
Tabela 10 - Quantidade de cooperativas que destinaram o mínimo exigido por lei para o FATES e FRL, por ano.

\begin{tabular}{ccc}
\hline ANO & FATES & FRL \\
\hline 2016 & 36 & 25 \\
2015 & 41 & 27 \\
2014 & 39 & 28 \\
\hline
\end{tabular}

Obs.: FATES: Fundo de Assistência Técnica Educacional e Social. FRL: Fundo de Reserva Legal. FATES possui taxa mínima de $5 \%$, conforme Lei ${ }^{\circ} 5 \cdot 764 / 71$. FRL possui taxa mínima de $10 \%$, conforme Lei $n^{\circ} 5 \cdot 764 / 71$.

Fonte: Dados da pesquisa.

A maioria das cooperativas destinou o mínimo exigido na lei 5764/1971. Quanto ao FATES, nenhuma cooperativa destinou mais de $15 \%$. Porém, quando analisado o Fundo de Reserva Legal, 1 cooperativa destinou $100 \%$ em 2015, além de haver outros valores expressivos como 60\% (1 cooperativa), $65 \%$ (4 cooperativas), $70 \%$ (1 cooperativa) e $75 \%$ de destinação (1 cooperativa). Destacase que estas reservas são obrigatórias antes da distribuição de resultado aos cooperados. Desta forma, a destinação integral das sobras a reservas obrigatórios impossibilita a destinação a outras reservas ou de forma divisível ser passível de utilização imediata, conforme apresentado por Barroso e Bialoskorski Neto (2010).

Ademais, visto a pouca participação dos cooperados nas decisões das cooperativas (FONTES FILHO; MARUCCI; OLIVEIRA, 20o8) e o conflito de agência existente com o cooperado-gestor (CUEVAS; FISCHER, 2006), este pode usar alocação em fundo não diviseis como uma forma de manter o patrimônio da cooperativa a fim de cumprir as exigências de Basileia. Esta política de distribuição de resultado, também pode está atrelada a uma forma de manutenção das atividades futuras das cooperativas.

A tabela 11 apresenta a ocorrência de outras reservas.

Tabela 11 - Ocorrência de outras reservas

\begin{tabular}{cccc}
\hline Outro Fundo & Frequência & Porcentagem & Acumulado \\
\hline Não & 43 & 74,14 & 74,14 \\
Sim & 15 & $\mathbf{2 5 , 8 6}$ & 100 \\
\hline Total & 58 & 100 \\
\hline \multicolumn{4}{c}{ Fonte: Dados da pesquisa. }
\end{tabular}

Ao ser perguntado se a cooperativa possuía outro fundo de reserva além do FATES e FRL, 15 cooperativas $(25,86 \%)$ responderam que possuíam. Este valor é relativamente baixo. Isto demonstra que as principais reservas são o FRL e FATES, principalmente por apresentarem em alguns casos, valores expressivos de destinação. Dada a existência de outros fundos, os nomes dos principais e a quantidade de cooperativas que o possuem estão listados na tabela 12.

Tabela 12 - Outros Fundos

\begin{tabular}{cc}
\hline Outros Fundos & Quantidade \\
\hline Fundo de Expansão & 5 \\
Fundo de Contingência & 4 \\
Fundo de Estabilidade Financeira (FEF) & 4 \\
Fundo de Ações Sociais & 1 \\
Fundo de Desenvolvimento & 1 \\
Fundo de Divulgação e Marketing & 1 \\
Fundo de Passivos Judiciais & 1 \\
Fundo de Tecnologia & 1 \\
Fundo para aumento de capital & 1 \\
Fundo Social & 1 \\
Fundo Social e Comunitário (FSC) & $\mathbf{1}$ \\
\hline TOTAL & $\mathbf{2 1}$ \\
\hline Fonte: Dados da pesquisa.
\end{tabular}


Os principais fundos presentes nas cooperativas analisadas são Fundos de Expansão (5 cooperativas), Fundo de Contingência (4) e Fundo de Estabilidade Financeira (FEF). Diferentes dos fundos indivisíveis, estes podem ser divisíveis e apresentam aplicações diversas, que estarão estabelecidas em estatuto social, quando se tratarem de fundos estatutários.

Destaca-se que alguns fundos se assemelham ao FATES, como o Fundo de Ações Sociais, o Fundo Social e o Fundo Social e Comunitário. Tais fundos podem ser alternativas para atuação social com programas voltados a comunidade, mas que, diferente do FATES que se trata de um passivo, integram o Patrimônio Líquido das cooperativas de crédito.

Na Lei Cooperativista está expresso que as sobras líquidas do período devem ser rateadas proporcionalmente às operações realizadas pelos cooperados e as formas de divisão devem estar previstas previamente nos estatutos (BRASIL, 1971). A tabela a seguir apresenta os resultados quanto ao uso da movimentação como critério de rateio das sobras líquidas (sobras após a destinação).

Tabela 13 - Formas de rateio das sobras líquidas

\begin{tabular}{cccc}
\hline Rateio por Movimentação & Frequência & Porcentagem & Acumulado \\
\hline Não & 3 & 5,17 & 5,17 \\
Sim & 50 & 86,21 & 91,38 \\
Não se aplica & 5 & 8,62 & 100,00 \\
\hline Total & $\mathbf{5 8}$ & $\mathbf{1 0 0 , 0 0}$ \\
\hline \multicolumn{4}{c}{ Fonte: Dados da pesquisa. }
\end{tabular}

Os rateios das sobras entre associados foram feitos de acordo com a proporção da movimentação de cada cooperado com a cooperativa em 50 das cooperativas. Dos respondentes, 8 informaram que a distribuição não era feita ou não se aplicava de acordo com a proporção da movimentação de cada cooperado. Os três casos que colocaram não correspondem: um a destinação total para o FATES, outro proporcional a rentabilidade gerada por cada associado e o terceiro alegou que a remuneração foi através de juros sobre o capital próprio. Quanto ao caso 'não se aplica' diz respeito às cooperativas que não apresentaram sobras ou obtiveram prejuízos no período analisado.

$\mathrm{O}$ rateio das sobras líquidas das cooperativas de crédito pode ser feito em conta corrente e conta capital, conforme Barroso e Bialoskorski Neto (2010). Quando devolvidas em conta corrente, as sobras são imediatamente disponibilizadas aos cooperados e quando devolvidas em conta capital não são devolvidas imediatamente. A tabela 14 apresenta os dados sobre a conta utilizada no rateio.

Tabela 14 - Conta de rateio das sobras

\begin{tabular}{ccccccc}
\hline Conta & $\mathbf{2 0 1 6}$ & $\mathbf{\%}$ & $\mathbf{2 0 1 5}$ & $\mathbf{\%}$ & $\mathbf{2 0 1 4}$ & $\mathbf{\%}$ \\
\hline Conta Capital & 44 & $75,86 \%$ & 48 & $82,76 \%$ & 45 & $77,59 \%$ \\
Conta Corrente & 14 & $\mathbf{2 4 , 1 4} \%$ & 10 & $17,24 \%$ & 6 & $10,34 \%$ \\
Ambas & o & 0,00\% & o & o,oo\% & 7 & $\mathbf{1 2 , 0 7 \%}$ \\
\hline Total & $\mathbf{5 8}$ & $\mathbf{1 0 0 , 0 0 \%}$ & $\mathbf{5 8}$ & $\mathbf{1 0 0 , 0 0 \%}$ & $\mathbf{5 8}$ & $\mathbf{1 0 0 , 0 0 \%}$ \\
\hline \multicolumn{7}{c}{ Fonte: Dados da pesquisa. }
\end{tabular}

Nota-se que das 58 cooperativas estudadas, a maioria teve suas sobras líquidas rateadas em conta capital, sendo a conta de rateio em mais de $70 \%$ das devoluções. Conforme abordado anteriormente, esta política pode está associada a um marketing da cooperativa. Com esta forma de distribuição de resultados, tem um impacto positivo direto na renda dos associados, funcionando como um mecanismo de aumento da atratividade de investimento, visto possuir baixa atratividade de investimento por não apresentar poder decisório atrelado ao número de quotas e pela baixa remuneração do capital investido (BESLEY, 1995; HANSMANN, 2000; CHADDAD; COOK, 2004).

Em seguida, foi realizada a classificação quanto a tipificação da distribuição de resultados aos cooperados de cooperativas de crédito de Barroso e Bialoskorski Neto (2010) (vide tabela 4). Os resultados são apresentados a seguir. 
175 | Política de distribuição de sobras em cooperativas de crédito

Tabela 15 - Tipos de Cooperativas conforme definição de Barroso e Bialoskorski Neto (2010)

\begin{tabular}{cccccccc}
\hline Tipo & $\mathbf{2 0 1 4}$ & $\mathbf{\%}$ & $\mathbf{2 0 1 5}$ & $\mathbf{\%}$ & $\mathbf{2 0 1 6}$ & $\mathbf{\%}$ & TOTAL \\
\hline I & 6 & $10,34 \%$ & 5 & $8,62 \%$ & 8 & $13,79 \%$ & 19 \\
II & 36 & $62,07 \%$ & 37 & $63,79 \%$ & 29 & $50,00 \%$ & 102 \\
III & 16 & $27,59 \%$ & 16 & $27,59 \%$ & 21 & $36,21 \%$ & 53 \\
\hline Total & 58 & $100,00 \%$ & 58 & $100,00 \%$ & 58 & $100,00 \%$ & 174
\end{tabular}

Obs.: Os tipos são: I (alguma parte das sobras devolvida em dinheiro na Conta Corrente dos cooperados), II (maior parte das sobras devolvida no Capital Social dos cooperados) e III (maior parte das sobras destinadas a reserva/provisões Indivisíveis).

Fonte: Dados da pesquisa.

Há o uso predominante da destinação das sobras na conta capital. Mais de $60 \%$ em 2014 e 2015 e 50\% em 2016. Tratam-se de cooperativas do tipo II (cooperativas que devolvem maior parte dos resultados nas contas capital social dos cooperados do que em reservas indivisíveis). Esta política vai de encontro com a manutenção das exigências de capital e também como formas dos gestores garantirem a sustentabilidade das cooperativas.

A segunda forma de distribuição frequente é a alocação de mais de 50\% das sobras em fundos indivisíveis (FATES e FRL). Essas cooperativas compreendem ao tipo III, e houve um aumento do uso desta forma de distribuição, passando de $27,59 \%$ em 2014 e 2015 para 36,21\%. E em menor quantidade há a destinação direta para a conta corrente do cooperado, que proporciona imediata retirada (tipo I). A ocorrência de alocação em fundos indivisíveis e em conta capital vão de encontro com a necessidade de patrimônio líquido das instituições. Conforme acordo de Basileia III, é necessário um capital mínimo para Cobertura do Risco de Crédito (BCB, 2019b). O uso das políticas de distribuição de resultado como uma forma de aumento de patrimônio líquido reforça a falta de atratividade do capital e necessidade de incentivo a investimento em cooperativas (BESLEY, 1995; MAIA; MENDES; COSTA, 2015).

\section{Conclusões}

O presente estudo buscou analisar a política de distribuição de sobras das cooperativas de crédito brasileiras. Para tanto, aplicou-se questionários para todas as cooperativas de crédito com emails disponíveis, e se obteve um total de 58 respostas válidas.

Um primeiro ponto a se destacar é a representatividade das cooperativas em todo território nacional. Conforme dados do FGCOOP (2017), essas organizações vêm exercendo um importante papel social, atuando em regiões nos quais as demais instituições financeiras não estão presentes. Este ponto vai de encontro aos estudos que levantam a importância das cooperativas (BARTON et al., 2011; SALES, 2010; BARROSO, 2009). E essa diversidade geográfica também ocorreu na amostra desta pesquisa.

Sobre o resultado das cooperativas, apesar de se tratarem de organizações que não possuem finalidade lucrativa (BRASIL, 1971), as cooperativas têm apresentando um saldo de sobras positivo e expressivo monetariamente. A presença de sobras em si, não contrapõe o papel social das cooperativas. Por outro lado, demonstra que além da gestão proporcionar um resultado financeiro positivo, esse excedente pode se transformar em investimentos futuros, levar a um crescimento das cooperativas que, aliado a uma boa gestão, se converta em benefícios para seus proprietários. $\mathrm{O}$ resultado financeiro positivo corrobora os achados de Barroso e Bialoskorski Neto (2010). Os autores perceberam um crescente aumento das sobras em trinta cooperativas de crédito rural do Estado de São Paulo.

Em relação aos fundos obrigatórios, a maioria das cooperativas segue a legislação vigente, alocando $10 \%$ para o fundo de Reserva Legal e $5 \%$ ao FATES. Entretanto, alguns casos de alocação de mais de $50 \%$ do total das sobras nestes fundos chamaram a atenção, isto porque se tratam de fundos indivisíveis, ou seja, não serão distribuídos aos cooperados mesmo se ocorrer a liquidação ou dissolução da cooperativa (BRASIL, 1971). Portanto, o valor destinado aos fundos indivisíveis pode não retornar ao cooperado, se o saldo do fundo não for utilizado ao que compete. Ressalta-se, assim, 
a importância da gestão na utilização destes fundos, principalmente no que tange ao FATES e sua alocação na educação cooperativista.

É importante destacar dois fatos importantes sobre o FATES. Primeiro que $100 \%$ do resultado do ato não cooperativo é destinado a este fundo e que para cooperativas de crédito (Lei 5764/71, art. 87 ), trata-se de um passivo e não patrimônio Líquido $(\mathrm{BCB}, 2006)$. Desta forma, não gera impacto no PL como cumprimento de exigência de patrimônio. Ademais, o valor empregado neste fundo pode estar associado a atos não cooperativos, que não foi considerado nesta pesquisa.

Quanto a conta de destinação, as sobras são majoritariamente destinadas à conta capital. Seguindo, portanto, a tipologia proposta por Barroso e Bialoskorski Neto (2010), as cooperativas analisadas são predominantemente do tipo II (maior parte das sobras devolvida no Capital Social dos cooperados) e do tipo III (maior parte das sobras destinadas a reserva/provisões indivisíveis), respectivamente. Os achados mostram a priorização de políticas de distribuição que gerem um aumento do patrimônio líquido. Este fato pode estar relacionado às exigências de capital mínimo, principalmente com a adoção do acordo de Basileia III.

Os achados reforçam também a baixa atratividade do capital em cooperativas e o problema de incentivo a investimento nestas organizações (BESLEY, 1995; MAIA; MENDES; COSTA, 2015). Esta falta de atratividade está associada aos problemas de direitos de propriedade das cooperativas que possuem vaga definição (COOK, 1995; CHADDAD; COOK, 2004). Fatores na legislação brasileira (Lei 5764/71) reforçam este cenário (direitos de propriedade vagamente definidos). O primeiro aspecto é o direito ao voto não ser atribuído ao capital e sim um homem, um voto. Desta forma, a aquisição de controle não gera incentivo a aquisição de mais quotas e maior integralização de capital. Segundo, a remuneração (juros) do capital é limitado a 12\% (BRASIL, 1971) e Selic (Sistema Especial de Liquidação e de Custódia) no caso das cooperativas de crédito (BRASIL, 2009). Uma baixa remuneração do capital desestimula a alocação de recursos, principalmente se considerada a visão de investidor frente a outras alternativas de aplicação dos recursos que proporcione maior retorno. Por fim, a devolução do capital é prevista na lei 5764/71 como um direito do cooperado, mas a regulação deste processo pode o tornar demorado pois compete ao Estatuto Social definir as condições de retirada, condições estas que não prejudiquem a situação financeira e econômica das cooperativas.

A falta de incentivo a investimento associada as exigências legais de capital mínimo para as cooperativas de crédito tornam a alocação a conta de capital e constituição de fundos uma estratégia plausível e, talvez, até necessária para estas organizações. Esta decisão estratégia visa proporcionar sustentabilidade para as cooperativas. Beneficia sua longevidade, seja pelo cumprimento das exigências legais ou pela utilização dos fundos no desenvolvimento de projetos, ampliação de atuação e impacto social. Por outro lado, o uso da distribuição via conta corrente, apesar de sua baixa adoção, pode fazer escopo de uma estratégia de marketing da cooperativa demonstrando, assim, para a sociedade a contínua e sistemática devolução do capital.

Os resultados demonstram um comportamento das cooperativas de crédito da amostra, que pode se espelhar em todo o sistema cooperativismo de crédito nacional. Os achados trazem à luz a política de distribuição das sobras adotadas pelas cooperativas e agregam informações úteis para os cooperados, assim como gestores de cooperativas e demais órgãos representantes do cooperativismo nos diferentes níveis geográficos.

Como principal limitação apresenta-se a baixa taxa de resposta obtida. Desta forma, para futuras pesquisas sugere-se a ampliação da amostra de análise e relacionar a política de distribuições com questões gerenciais e financeiras, inclusive sua relação com o Îndice de Basileia.

\section{Agradecimentos}

As autoras agradecem à FAPEMIG (Fundação de Amparo à Pesquisa do Estado de Minas Gerais) o apoio recebido para realização desta pesquisa. 


\section{Referências}

BARROSO, M. F. G. Distribuição de resultados e desempenho de cooperativas de crédito: estudo comparativo no estado de São Paulo. 2009. tese - Universidade de São Paulo, Ribeirão Preto, 2009. Disponível em: http://www.teses.usp.br/teses/disponiveis/96/96133/tde-29042009-091356/. Acesso em: 13 nov. 2019.

BARROSO, M. F. G.; BIALOSKORSKI NETO, S. Distribuição de resultados em cooperativas de crédito rural no Estado de São Paulo. Organizações Rurais \& Agroindustriais, v. 12, n. 2, p. 290$307,2010$.

BARTON, D. et al. Current Challenges in Financing Agricultural Cooperatives. The Magazine of Food, Farm and Resource Issues, v. 26, n. 3, 2011.

BCB. Banco Central do Brasil. Disponível em: http://www.bcb.gov.br/pt-br/\#!/home. Acesso em: 19 fev. 2019a.

BCB. Carta Circular 3224, de 03 de fevereiro de 2006. Esclarece acerca da base de cálculo do Fundo de Assistência Técnica, Educacional e Social - Fates para cooperativas de crédito. , 2006.

BCB. Panorama do sistema nacional de crédito cooperativo. . Brasília: Banco Central do Brasil, 2017.

BCB. Recomendações de Basileia. Disponível em: https://www.bcb.gov.br/estabilidadefinanceira/recomendacoesbasileia. Acesso em: 20 maio 2019b.

BERLE, A.; MEANS, G. C. The modern corporation and private property. New York: Macmillan, 1932.

BESLEY, T. Property Rights and Investment Incentives: Theory and Evidence from Ghana. Journal of Political Economy, v. 103, n. 5, p. 903-937, 1995.

BRASIL. Lei Complementar $\mathrm{n}^{\mathrm{o}}$ 130, de 17 de abril de 2009. Dispõe sobre o Sistema Nacional de Crédito Cooperativo e revoga dispositivos das Leis nos 4.595, de 31 de dezembro de 1964, e 5.764, de 16 de dezembro de 1971. , 2009.

BRASIL. Lei $n^{0}$ 5764, de 16 de dezembro de 1971. Define a Política Nacional de Cooperativismo, institui o regime jurídico das sociedades cooperativas e dá outras providências. , 1971.

CHADDAD, F.; COOK, M. Understanding New Cooperative Models: An Ownership-Control Rights Typology. Review of Agricultural Economics, v. 26, p. 348-360, 1 fev. 2004.

CMN. Resolução $n^{\circ}$ 4194, de 1 de março de 2013. Dispõe sobre a metodologia facultativa para apuração dos requerimentos mínimos de Patrimônio de Referência (PR), de Nível I e de Capital Principal para as cooperativas de crédito que optarem pela apuração do montante dos ativos ponderados pelo risco na forma simplificada (RWARPS) e institui o Adicional de Capital Principal para essas cooperativas. 2013. Disponível em: https://www.bcb.gov.br/estabilidadefinanceira/exibenormativo?tipo=Resolu\%C3\%A7\%C3\%A3o\& numero=4194. Acesso em: 13 nov. 2019.

CMN. Resolução $\mathrm{n}^{\circ}$ 4606, de 19 de outubro de 2017. Dispõe sobre a metodologia facultativa simplificada para apuração do requerimento mínimo de Patrimônio de Referência Simplificado (PRS5), os requisitos para opção por essa metodologia e os requisitos adicionais para a estrutura 
simplificada de gerenciamento contínuo de riscos. , 2017. Disponível em: https://www.bcb.gov.br/estabilidadefinanceira/exibenormativo?tipo=Resolu\%C3\%A7\%C3\%A3o\& numero=4606. Acesso em: 13 nov. 2019.

CMN. Resolução n ${ }^{\circ} 4434$, de 5 de agosto de 2015. Dispõe sobre a constituição, a autorização para funcionamento, o funcionamento, as alterações estatutárias e o cancelamento de autorização para funcionamento das cooperativas de crédito e dá outras providências. , 2015.

COOK, M. L. The Future of U.S. Agricultural Cooperatives: A Neo-Institutional Approach. American Journal of Agricultural Economics, v. 77, n. 5, p. 1153-1159, 1995.

COSTA, D. R. DE M.; CHADDAD, F. R.; AZEVEDO, P. F. DE. Separação entre propriedade e decisão de gestão nas cooperativas agropecuárias brasileiras. Revista de Economia e Sociologia Rural, v. 50, n. 2, p. 285-300, jun. 2012.

COSTA, E. G.; MELO, A. A. DE O. Governança Corporativa: Conflitos de Agência em Cooperativas de Crédito Mineiras. Gestão \& Planejamento, v. 18, p. 386-409, 11 abr. 2017.

CUEVAS, C. E.; FISCHER, K. P. Cooperative Financial Institutions: Issues in Governance, Regulation, and Supervision. [S.1.]: The World Bank, 2006. Disponível em: http://elibrary.worldbank.org/doi/book/10.1596/978-0-8213-6684-4. Acesso em: 1 abr. 2020. (World Bank Working Papers).

DAVIS, K. Credit Union Governance and Survival of the Cooperative Form. Journal of Financial Services Research, v. 19, n. 2, p. 197-210, 1 abr. 2001.

FAIRBAIRN, B. et al. Credit unions and community economic development. Saskatoon: Centre for the Study of Co-operatives, University of Saskatchewan, 1997.

FGCOOP. Relatório do Sistema Nacional de Crédito Cooperativo - SNCC. . [S.1: s.n.], 2017.

FONTES FILHO, J. R.; MARUCCI, J. C.; OLIVEIRA, M. J. DE. Governança cooperativa: participação e representatividade em cooperativas de crédito no Brasil. Revista de Contabilidade e Organizações, v. 2, n. 4, p. 107-125, 1 dez. 2008.

FRANKE, W. Direito das Sociedades Cooperativas: Direito Cooperativo. [S.1: s.n.], 1973.

GIL, A. C. Métodos e Técnicas de Pesquisa Social. 6 ${ }^{\mathrm{a}}$ ed. São Paulo: Atlas, 2008. Disponível em: https://ayanrafael.files.wordpress.com/2011/08/gil-a-c-mc3a9todos-e-tc3a9cnicas-de-pesquisasocial.pdf. Acesso em: 1 maio 2018.

HANSMANN, H. The ownership of enterprise. London: Harvard University Press, 2000.

JENSEN, M.; MECKLING, W. Theory of the firm: managerial behaviour, agency costs and ownership structure. Journal of Financial Economics, v. 3, p. 305-360, 1976.

JUCÁ, M. N. Determinantes da estrutura de capital de bancos brasileiros e norte-americanos. 2011. tese - Universidade de São Paulo, 2011. Disponível em: http://www.teses.usp.br/teses/disponiveis/12/12139/tde-27012012-192849/. Acesso em: 13 nov. 2018. 
KALUF, M. A. B. A responsabilidade do associado perante a cooperativa de crédito. In: SENRA, R. B. DE F. (Org.). . Aspectos Jurídicos das Cooperativas de Crédito. $1^{\mathrm{a}}$ ed. Belo Horizonte: Mandamentos, 2005. p. 217-245.

LAUSCHNER, R. Agroindústria cooperativa. In: PINHO, D. B. Tipologia cooperativa - Manual de cooperativismo. São Paulo: CNPQ, 1984. v. 4. p. 76-84.

LIMA, R. E. DE; ARAÚJO, M. B. V. DE; AMARAL, H. F. Conflito de agência: um estudo comparativo dos aspectos inerentes a empresas tradicionais e cooperativas de crédito. Revista de Contabilidade e Organizações, v. 2, n. 4, p. 148-157, 1 dez. 2008.

LONDERO, P. R.; SANTOS, A. DOS. ICPC 14: Os Impactos dessa Norma Contábil nas Sociedades Cooperativas Agropecuárias. Sociedade, Contabilidade e Gestão, v. 14, n. 1, 2019.

MAIA, L. L.; MENDES, D. H.; COSTA, D. R. DE M. Direitos De Propriedade E Incentivos Ao Investimento: Aplicação Em Cooperativas De Crédito Do Estado De São Paulo. 2015, São Paulo. Anais... São Paulo: [s.n.], 2015. Disponível em: http://sistema.semead.com.br/18semead/resultado/trabalhosPDF/1045.pdf. Acesso em: 17 nov. 2019.

MUNHOS, J. L. Governança Corporativa: Fundamentos, Principais Modelos e Aplicação nas Cooeprativas no Brasil. In: BAGGIO, A. F. Governança corporativa, cooperativa e territorial: teorias e experiências nacionais e internacionais a estratégia vencedora. Porto Alegre: Sescoop, 2018. .

OBSERVATÓRIO DE COOPERATIVAS. Quantidade De Operações De Crédito Nas Cooperativas Cresce A Taxas Acima Das Encontradas Bancos Comerciais. OBSCOOP. Disponível em: http://obscoop.fearp.usp.br/dp7/blog/quantidade-de-operações-de-crédito-nas-cooperativascresce-taxas-acima-das-encontradas-bancos. Acesso em: 19 abr. 2019.

OCB. Ramos do Cooperativismo. Disponível em: 〈https://www.ocb.org.br/ramos〉. Acesso em: 28 ago. 2019.

PHILLIPS, R. Economic Nature of the Cooperative Association. American Journal of Agricultural Economics, v. 35, n. 1, p. 74-87, 1953.

PINHO, D. B. Economia e Cooperativismo. São Paulo: Saraiva, 1977.

POLONIO, W. A. Manual das sociedades cooperativas. $3^{\text {a }}$ ed ed. São Paulo: Atlas, 2001.

PORTAL DO COOPERATIVISMO FINANCEIRO. Portal do Cooperativismo Financeiro. Disponível em: http://cooperativismodecredito.coop.br/. Acesso em: 3 jul. 2017.

SALES, J. E. Cooperativismo: Origens e Evolução. Revista Brasileira de Gestão e Engenharia, p. $12,2010$.

SEBRAE. Causas Mortis: O sucesso e o fracasso das empresas nos primeiros 5 anos de vida. . [S.l: s.n.]. Disponível em: http://www.sebrae.com.br/Sebrae/Portal\%20Sebrae/UFs/SP/Anexos/causa_mortis_2014.pdf. Acesso em: 1 jun. 2019. , 2014

SELLTIZ, C.; WRIGHTSMAN, L. S.; COOK, S. W. Métodos de pesquisa das relações sociais. São Paulo: Herder, 1965. 
SOARES, M. M.; MELO SOBRINHO, A. DE. Microfinanças o papel do banco central do Brasil e a importância do cooperativismo de credito. Brasilia (Brasil): BCD, 2008.

TAYLOR, R. A. The Credit Union as a cooperative institution. Review of social economy., 1971.

VERGARA, S. C. Projetos e relatórios de pesquisa em administração. 3. ed. Rio de Janeiro: Atlas, 2000. 